\title{
DE LOS CÓDIGOS ÉTICOS EN LAS EMPRESAS A LOS CÓDIGOS DE CONDUCTA Y DISTINTIVOS DE CONFIANZA EN EL E- COMMERCE
}

\author{
Nuria Belloso Martín
}

\section{RESUMEN}

En las actividades de la empresa y de los negocios, junto a la estrategia de compras, ventas o beneficios, resulta necesario introducir estándares morales. Hay que saber discernir qué puede aportar la experiencia empresarial a la ética de la empresa a la vez que también hay que saber valorar qué puede aportar la ética al funcionamiento correcto de la empresa. La Ética obliga a las empresas a evaluar la calidad de la conducta con la que se alcanzan los objetivos, si la conducta es moral o no, si es justa o injusta. Los protocolos de buenas prácticas y los códigos de conducta empresarial permiten una mejor interrelación entre empresa y Ética. Por otro lado, las nuevas tecnologías y, especialmente Internet, plantean nuevos retos para las exigencias de la Ética. La colonización de Internet por parte del business ha determinado el fracaso de los mecanismos de autorregulación que funcionaban anteriormente. De ahí que se haga necesario el diseño de códigos éticos interactivos, entre los que cabe destacar el Código Ético de Publicidad Interactiva y Comercio por Internet, así como el Distintivo Público de Confianza en Línea. Todo ello revestido de un tinte ético que ayudará a prestigiar más a la propia empresa y los negocios que lleve a cabo. La reivindicación de la Ética y de los valores reviste de un plus de legitimidad a las empresas.

\section{Sumario}

1. Sobre estándares morales y Ética.- 2. Ética y valores en la empresa y en los negocios-3. Calidad en la empresa.- 4. La empresa como sujeto de responsabilidad ética.- 5. Principios éticos de la gestión empresarial.- 6 . Código de conducta empresarial.- 7. Nuevas tecnologías y códigos éticos interactivos: 7.1. Ética y sistema de información; 7.2. Código ético de publicidad interactiva y comercio por Internet.- 8. Distintivo Público de Confianza en Línea.- 9. A modo de conclusión.

\section{SOBRE ESTÁNDARES MORALES Y ÉTICA}

Definir qué sea la Ética no es una cuestión pacífica. Las respuestas que nos pueden ofrecer quienes no son expertos en la materia pueden ir desde "ético es lo que mis sentimientos me dicen que es correcto. Pero esto no es un estándar fijo, y puede dar lugar a problemas" a aquéllos otros que consideran que "ético significa estándares aceptados en términos del bienestar personal y social; lo que uno cree que está bien. Pero, ¿y si yo he tenido una mala guía? 
Tal vez cada uno de nosotros piensa que sabe lo que es ético, pero diferimos. ¿Cómo se sabría, entonces, lo que es correcto?”.

Ética y moral parecen ser términos indistintos pero tienen etimologías diferentes. "Ética" es un término que deriva del griego ethos -"carácter", en tanto modo de ser culturalmente adquirido, adquirido por el hábito-. Por su parte, "moral" es un término que deriva del latín mos, moris -"costumbre", "tradición", etc. Ética no es lo mismo que moralidad. La ética es moral racional y dialógicamente argüible, y por lo tanto, "públicamente argüible", apelando a la razón pública y sin constreñirse a razones privadas ${ }^{2}$. Por tanto, para comprender qué sea Ética debemos partir de la moralidad.

Se podría definir la moralidad como los estándares que tiene un individuo o un grupo acerca de qué es correcto o incorrecto, o lo que está bien o está mal. Y, ¿cuáles son las características que distinguen a los estándares morales de los que no lo son? Se pueden enumerar cinco características que ayudan a establecer la naturaleza de los estándares morales: 1) Manejan asuntos que creemos dañarían o beneficiarían significativamente a las personas (por ejemplo, robo, violación, esclavitud, asesinato, abuso de menores, etc.); 2) No se establecen o cambian por la decisión de cuerpos de autoridad específicos. Las leyes y los estándares legales sí están establecidos por la autoridad legislativa o la decisión de los votantes. La validez de los estándares morales se apoya en la suficiencia de las razones que los justifican; 3) Sentimos que los estándares morales deben preferirse a otros valores incluso al interés personal. Es decir, si una persona tiene obligación moral de hacer algo, entonces se espera que lo haga, aunque cuando esté en conflicto con otros valores, no morales, o con el interés personal; 4) Por lo general, los estándares morales se basan en consideraciones imparciales. Que uno se beneficie con una mentira y otro reciba un daño es irrelevante para decidir si mentir es moralmente incorrecto; 5) Están asociados con emociones y vocabulario especiales. Por ejemplo, si yo actúo en contra de un estándar moral, normalmente me sentiré culpable, avergonzado y con remordimiento: clasificaría mi comportamiento como "inmoral" o "erróneo" 3.

En definitiva, los estándares morales son los que se refieren a asuntos cuyas consecuencias creemos son serias, se basan en las buenas razones y no en la autoridad, invalidan el interés personal, se basan en consideraciones imparciales, están asociados con sentimientos de culpa y vergüenza, y tienen un vocabulario moral especial. Estos estándares son productos de muchas influencias, los asumimos en nuestra etapa de infancia y los corregimos conforme maduramos

Ética es la disciplina que examina los estándares morales personales o los estándares morales de una sociedad. Pregunta cómo se aplican estos estándares a nuestras vidas y si son razonables o irrazonables, es decir, si están apoyados por buenas razones o por razones pobres. Ética es la parte de la Filosofía que se ocupa de la moral y de las obligaciones del ser humano considerado en su individualidad. Como apunta O. Diego, la Ética es la "disciplina del conocimiento que tiene por objeto el estudio de los distintos caracteres, hábitos, costumbres y actitudes del ser humano, y clasifica las 
acciones en buenas o malas, debidas o indebidas, convenientes o nocivas, en virtudes y vicios, y enseña cuáles son aquellas dignas de imitar ${ }^{4}$.

Por naturaleza el hombre pertenece al género animal, pero a diferencia de éste tiene desarrollada la habilidad del razonamiento, del análisis y la reflexión, cualidades que a su vez se basan en la capacidad de percepción y en la inteligencia. Cuando desarrolla dichos elementos llega a un grado de comprensión que le permite discernir lo benéfico de lo nocivo. En la medida en que razona sobre si es conveniente o no realizar un determinado acto y elige, entra en el campo de la Ética. En la disciplina de la Ética existe una lógica de lo que es honesto, conveniente y debido, en contraposición a lo deshonesto, inconveniente e indebido.

La Ética personal se ocupa de todas las acciones realizadas por la persona individual en cuanto tal, también de aquellas que se refieren a la sociedad política tales como pagar impuestos, pero en cuanto que son personales. Por su parte, la Ética política se ocupa de las acciones realizadas por la sociedad política. Dirige los actos a través de los cuales la sociedad política se da a sí misma una forma y una organización constitucional, jurídica, fiscal, administrativa, etc., valorando esta estructuración desde el punto de vista del fin propio de la comunidad política en cuanto tal. Entendemos que no hay más que una Ética, la vinculada a la idea del hombre, que se pone de manifiesto en la vida social, familiar, profesional y política del individuo. No existen dos morales, una pública -cuyo ámbito sería la vida en sociedad- y otra privada - destinada a dirigir la vida personal e individual- sino que son dos manifestaciones distintas de una misma realidad: dos dimensiones diferentes de un mismo fenómeno, como es el comportamiento ético ${ }^{5}$.

Consideramos que la teoría que sustenta G. Peces-Barba acerca de que la Ética puede dividirse en ética pública y ética privada, alude a los ámbitos en los que la Ética se puede proyectar, pero ello no está reñido con sustentar una única Ética. Como subraya G. Peces Barba, la ética privada parte de la idea de la igual dignidad humana y supone un camino para alcanzar la autonomía o independencia moral, un proyecto final de salvación o para alcanzar el bien, la virtud o la felicidad y puede ser religioso o laico ${ }^{6}$. La ética pública, por su parte, conforma el orden justo y estable, libre, igual y solidario y los criterios de organización de la vida social y de los poderes, el conjunto de valores, principios y derechos ${ }^{7}$.

En los últimos años se ha presentado con mayor urgencia la exigencia de regular éticamente el capitalismo, la necesidad de repensar los valores comunitarios, la necesidad de lograr una ciudadanía participativa, guiada por valores de civismo y tolerancia. A su vez, los diversos enfoques, posiciones, perspectivas y visiones del orden moral hacen más compleja la situación ${ }^{8}$. El enfoque relativista actual basado en el "todo vale" o "todo vale lo mismo" se aplica, indiscriminadamente, a las diversas áreas de actuación de los sujetos: Administración pública, política, negocios, empresa, etc.

Nuestra preocupación no se refiere a la Ética en general sino a un campo particular de ella: la ética en la empresa y en los negocios, viendo lo No 35|P. 101-129| JAN-JUN 2011 
que es moralmente correcto o incorrecto. Se concentra en los estándares morales que se aplican a las instituciones, las organizaciones y el comportamiento en los negocios?

\section{2 ÉTICA Y VALORES EN LA EMPRESA Y EN LOS NEGOCIOS}

Tratar de la Ética relacionada con el mercado y los negocios, suele causar cierta extrañeza. Ello obedece a que solemos identificar mercado y negocios con beneficios y eficacia, dejando de lado la Ética. Se piensa que, si en los negocios se actúa siguiendo unos principios éticos, el beneficio se verá reducido. La eficacia tiene relación directa con la rentabilidad. La disparidad de objetivos entre la eficacia y la Ética en materia de negocios, en apariencia, muestra a ambas realidades más enfrentadas que próximas. $Y$ la falacia se produce precisamente cuando se identifica mercado o economía con eficacia. Como apunta V. Labrada, desde una perspectiva ética, la economía es el arte de aprovechar y distribuir bienes y recursos escasos y tiene como objetivo alcanzar la máxima producción y la mejor distribución en las circunstancias concretas de cada momento y lugar. Identificar mercado únicamente con eficacia y rentabilidad a cualquier coste económico o social aleja y llega a oponer los campos del mercado con la Ética" ${ }^{10}$.

La actual crisis que padecemos ha sido diagnosticada, por numerosos expertos, como la consecuencia de haber abandonado la Ética a la hora de ocuparse de los negocios ${ }^{11}$. De ahí que haya que reivindicar la presencia de la Ética en las empresas. La Comisión Europea recomienda ofrecer en los estudios de empresariales cursos o módulos de ética empresarial ${ }^{12}$. El objetivo es ofrecer una visión social del desarrollo que compense el individualismo propio de la sociedad de bienestar y abonar el terreno para el futuro profesional de nuestros alumnos egresados. A su vez, las empresas con directivos consecuentes implantarán una cultura empresarial socialmente responsable.

El discurso de los valores es objeto de marketing por parte de las empresas: los códigos de conducta, los comités de ética que tratan de mejorar la imagen institucional de la empresa, etc. Las empresas no se limitan a vender sus productos sino que desean tener un mínimo de legitimidad. En ocasiones patrocinan actividades de carácter social o incorporan valores sociales a su publicidad $^{13}$.

Antes de proseguir nuestra exposición, conviene que delimitemos adecuadamente los términos, ya que suele producirse cierta confusión entre Ética, Moral y Deontología. La deontología profesional está directamente relacionada con la ética de las profesiones jurídicas de manera que no se puede tratar de deontología sin ética. Ya hemos definido -en el primer epígrafe- lo que es Ética. Por su parte, Deontología es la ciencia o tratado de los seres humanos pero considerados en su conjunto. Por ello, Deontología es la ciencia que se ocupa de determinar las formas de comportamiento que debe seguir un ser humano en el ejercicio de su actividad profesional dentro del grupo que se integra ${ }^{14}$. 
Con todo, una parte de la doctrina esgrime una serie de razones en contra de las codificaciones deontológicas, entre las que podemos destacar cinco: a) Peligro de cristalización en principios que de por sí exigen elasticidad; b) Peligro de reprimir la competencia profesional y de tutelar unilateralmente a los inscritos en el registro colegial; c) Peligro de que la codificación ofusque de alguna manera la libertad profesional; y d) Peligro de relajamiento de la responsabilidad minimizando la capacidad moral de cada individuo; e) Los códigos deontológicos acaban mezclando e incluso confundiendo los principios de comportamiento con los deberes concretos. Como acertadamente subraya M. Otero, todas estas objeciones tienen una parte de verdad pero se las puede dar una única respuesta con carácter general. Y es que sería deseable que no fuera preciso establecer normas de conducta, fiándose únicamente de la moral y el buen hacer de cada uno, pero lo cierto es que la realidad no sigue esta línea y, por ello, hay que postular la necesidad de unos códigos de deontología profesional y dotarlos de fuerza jurídica y moral ${ }^{15}$. Las normas deontológicas explícitas 0 implícitas en profesiones tradicionales y liberales son muy antiguas $^{16}$.

Independientemente de las modas, la ética empresarial resulta imprescindible en todo negocio. "Porque la encarnación de ese inhumano homo oeconomicus, extremadamente desprovisto de responsabilidad cívica" deber ser reemplazado por el hombre responsable y ético que proyecta una imagen de empresa ética y socialmente responsable.

La valoración del nivel de Ética practicada en cada empresa y en los negocios debe efectuarse por los empleados, clientes, proveedores, consumidores y todos los interlocutores afectados. $Y$ es que la rentabilidad de la Ética en los negocios resulta indudable. "A largo plazo, la ética en el mundo de los negocios resulta muy rentable" ya que una compañía ética compite como las demás, pero suma una cuestión intachable de confianza y de imagen ante los clientes ${ }^{17}$.

En Europa hay algunas redes de Ética empresarial EBEN (European Bussiness Ethics Networks) y, en España, la Fundación valenciana ETNOR (Fundación para la Ética de los Negocios y las Organizaciones). Recientemente, la Fundación Gregorio Peces-Barba para el Estudio y Cooperación en Derechos Humanos, en la Universidad Carlos III de Madrid, ha constituido la Cátedra de "Ética de la Empresa y de las Profesiones" 18 , iniciativa que alabamos. La Ética de los negocios parte de los supuestos de que la Ética es rentable, pues disminuye costes de organización y potencia una imagen de la organización que favorece su competitividad ${ }^{19}$.

\section{CALIDAD EN LA EMPRESA}

Los sistemas de calidad de la empresa, que van desde la calidad del producto a la calidad del conjunto de la organización, introducen en la gestión de la empresa unos principios y valores en torno a los cuales nace la denominada cultura empresarial, que es el estilo de afrontar el negocio, la actividad profesional y el conjunto de la organización empresarial. 
En 1945, en España, el Consejo Superior de Investigaciones Científicas creó IRANOR, que diseñó las primeras normas con las siglas UNE conforme a las prescripciones internacionales. Desde 1986 la actividad de normalización y certificación $(\mathrm{N}+\mathrm{C})$ en España está a cargo de AENOR, entidad privada, independiente, sin ánimo de lucro, reconocida en los ámbitos nacional, comunitario e internacional, que contribuye a mejorar la calidad de las empresas, de sus productos y servicios, protegiendo el medio ambiente y el bienestar social.

AENOR tiene como objetivo elaborar normas técnicas españolas con la participación abierta a todas las partes interesadas, así como certificar productos y servicios de las empresas. Las normas de calidad establecidas por la Organización para la Estandarización (ISO) son estándares y guías relacionadas con sistemas de gestión.

El denominado Sistema de Gestión de Calidad -SGC- es el conjunto de procesos de la empresa que se propone planificar la calidad de la actividad con el objetivo de una mayor satisfacción del cliente interno y externo. La implantación en las organizaciones supone un esfuerzo que ofrece importantes ventajas, entre las que destacan la reducción de rechazo e incidencias en la producción o prestación del servicio, el aumento de la productividad y la mejora continua. El Sistema de Gestión de la Calidad se configura como el conjunto de elementos interrelacionados de una empresa u organización por los cuales se administra de forma planificada la calidad de la misma, en la búsqueda de la satisfacción de sus clientes. Se basa en cinco puntos:

1. La estructura de la organización: responde al organigrama de la empresa donde se jerarquizan los niveles directivos y de gestión.

2. La estructura de responsabilidades: implica a personas y a departamentos. La forma más sencilla de explicitar las responsabilidades en calidad es mediante un cuadro de doble entrada, donde mediante un eje se sitúan los diferentes departamentos y, en el otro, las diversas funciones de la calidad.

3. Procedimientos: responden al plan permanente de pautas detalladas para controlar las acciones de la organización.

4. Procesos: responden a la sucesión completa de operaciones dirigidos a la consecución de un objetivo específico.

5. Recursos: no solamente económicos, sino humanos, técnicos y de otro tipo, deberán estar definidos de forma estable y, además, de forma circunstancial

Algunos autores han subrayado las diferentes metodologías de la Asociación Internacional de Institutos -ISO- con la de la Fundación Europea de Gestión de la Calidad-EFQM-. El enfoque de calidad de ISO propone normas de unificación en ámbitos científicos, médicos y técnicos que regulan procedimientos, modelos de conducta, formas de medida y documentación, de manera que la aplicación de dichas normas prueba la implantación de las políticas de calidad. Sin embargo, el enfoque de calidad de EFQM, que con apoyo de la Comisión Europea persigue el objetivo de mejorar la calidad, la 
satisfacción del cliente y del trabajador y la incidencia social de las empresas, no establece normas sino que identifica las mejores prácticas de las organizaciones más reputadas ${ }^{20}$.

EFQM distingue a aquellas organizaciones que siguen una estrategia orientada hacia la excelencia y han logrado alcanzar los objetivos marcados. El sistema otorga prestigio a las organizaciones, ya que sólo se reconocen las que cumplen con la seguridad y profesionalidad probada por el personal cualificado que interviene e interactúa en la evaluación de la organización. El sistema se materializa en cuatro distinciones, correspondientes a otros tantos niveles de excelencia en la gestión, en los que se puede encontrar la organización con respecto al modelo EFQM de excelencia. Las organizaciones y empresas que optan por este proceso gozan de mejor imagen y obtienen beneficios en todos los sentidos tanto en relación a sus accionistas como a sus trabajadores y la sociedad en general.

La calidad guarda una estrecha relación con la Ética. Las principales razones que han impulsado la preocupación por la Ética son: a) Pérdida de la credibilidad depositada en las empresas; b) Insuficiencia del derecho; c) Protagonismo creciente de la empresa en el desarrollo, no sólo económico y social; d) Necesidad creciente de armonizar los intereses globales de la empresa con los de cada uno de sus miembros.

\section{LA EMPRESA COMO SUJETO DE RESPONSABILIDAD ÉTICA}

La cultura empresarial está formada por los principios, valores, creencias, motivaciones y actitudes que marcan un estilo de gobierno y trabajo en la organización. "La cultura de una empresa, sea positiva o negativa, crea una identidad dentro y fuera de ella, identidad por la que la empresa es valorada además de por su rentabilidad y profesionalidad" 21 .

Los valores contienen elementos de juicio que permiten a los individuos discernir sobre lo que es bueno, correcto y deseable. A su vez, los valores se apoyan sobre los principios morales que orientan los comportamientos y las relaciones humanas de la sociedad y sirven de base para el comportamiento ético. La Ética se convierte así en el conjunto de reglas que gobierna el ordenamiento de los valores.

En el ámbito de la empresa se trata de practicar virtudes, cualidades y actitudes en la conducta profesional, tales como la honestidad o integridad y el compromiso social, de evitar la maledicencia, la difamación y la mentira, de respetar la palabra dada y los compromisos asumidos, la capacidad de mejorar admitiendo sugerencias ajenas, la confianza en los demás, el trato excelente con el cliente, la templanza, la flexibilidad, actitud de innovación, prudencia, generosidad, disposición para el servicio y la sencillez de trato, el optimismo, el control de la ira, la puntualidad, la empatía, la visión global de la realidad, la justicia en las decisiones y la fortaleza amable en la exigencia, la obediencia inteligente y responsable. 
Junto a la estrategia de compras, ventas o beneficios, introducir en los negocios la referencia a la Ética obliga a las empresas a evaluar la calidad de la conducta con la que se alcanzan los objetivos. Hay que evaluar la forma en cómo se han alcanzado los objetivos, si la conducta es moral o no, si es justa o injusta. La libertad, incluso en circunstancias adversas, permite que la persona asuma compromisos y deberes como sujeto de responsabilidad ética y jurídica ${ }^{22}$.

Desde una perspectiva individualista de la Ética como algo subjetivo y personal, se puede llegar a la errónea conclusión de que la empresa no es sujeto de responsabilidad ética. Por el contrario, hay que afirmar que la empresa, como institución, tiene responsabilidad ética. La organización de la empresa, los directivos y hombres de negocio deben tener presentes principios morales en todo el proceso de planificación y control del negocio. La organización tiene responsabilidad ética al igual que la tiene jurídica. Y al igual que los directivos tienen responsabilidad ética también los empleados la tienen. La imagen de una empresa, como institución, se beneficia o perjudica por el conjunto de la actividad de los que la integran. La falta de ética en una empresa acaba pasando factura.

Los problemas éticos surgen cuando la toma de decisiones debe hacer frente a un conflicto de intereses que a su vez encubre un conflicto de valores. Habrá que sopesar el problema, el beneficio, las posibles pérdidas, la legalidad, la repercusión en los medios de la decisión que se adopte, valorar el respeto a los principios éticos, etc.

Asimismo, hay que recordar el alcance, también en la ética empresarial, de la cooperación en acciones no éticas que se oponen al deber general de no incurrir en maledicencia. Se entiende por cooperación al mal cualquier ayuda que se presta a la acción errónea de otro. El Código Penal califica de ilícitas las acciones del mandante, inductor, cómplice, encubridor e intermediario porque cooperan a un acto ilícito. Junto a la responsabilidad conjunta de la empresa como institución está la responsabilidad personal de cada directivo o empleado ${ }^{23}$.

En los negocios, como en otros tantos ámbitos, hay argumentos que tratan de justificar la cooperación al mal: "yo cumplo con mi deber, no tengo otra alternativa"; "no puedo cambiar las circunstancias"; "debe hacer lo que se me ordena y cumplir los objetivos que se me encomiendan". Pero estos argumentos no eximen de responsabilidad. El gran interrogante que surge es si se puede exigir a los directivos y empleados la Ética al igual que se exige alcanzar los resultados propuestos ${ }^{24}$.

La cooperación de las empresas en acciones no éticas pueden presentarse en ${ }^{25}$ :

- Aspectos de ventas: sobornos, robos de secretos industriales

- Aspectos de publicidad: anuncios falsos y engañosos

- Aspectos de la distribución: tratos exclusivos

- Aspectos de producto: garantías, servicios, protección de patentes

- Aspectos de la presentación: rótulos adecuados 
- Aspectos de precios: políticas de fijación de precios

- Aspectos competitivos: barreras de ingreso, competencia desleal

- Aspectos de producción y adquisición de materias primas: calidad de procesos y el impacto ambiental

- Aspectos laborales: tipo de contrataciones, retribución del esfuerzo, calidad de las relaciones y bienestar común.

\section{PRINCIPIOS ÉTICOS DE LA GESTIÓN EMPRESARIAL}

Hemos dejado claro que el respeto por los principios éticos atañe a todos los trabajadores y empleados de la empresa, aunque hay que reconocer que la acción empresarial de directivos tiene una especial repercusión en el contexto del negocio.

Los principios que deben guiar los negocios ${ }^{26}$ son:

a) El principio de legalidad: exige de los directivos y de la gestión empresarial el cumplimiento de la ley nacional e internacional. Entre la legalidad y la Ética hay un breve espacio que hay que proteger. A mayor nivel ético de comportamiento empresarial, menor riesgo de conducta ilegal en la gestión del negocio. Por el contrario, si hay un descenso u omisión de la Ética en la gestión empresarial aumenta el riesgo de infracción legal.

b) El principio de respeto a la integridad de las personas: la dignidad de la persona exige el respeto al conjunto de su identidad, que incluye la dimensión psíquica, espiritual y física.

c) El de profesionalidad: fomenta la actualización y la preparación técnica de los trabajadores y especialmente de los directivos. El principio de profesionalidad se rige a su vez por el principio de beneficencia, que exige que el fin propuesto en el desarrollo del negocio, así como los medios empleados y la estrategia para alcanzarlo, sean honestos.

d) El principio de veracidad y transparencia: abarca diversas posibilidades tales como en compraventa, en publicidad y promociones, en auditoria, en precio, en información de personas, en información de acontecimientos, en evaluación de subordinados, en los compromisos.

e) El principio de buena fe, el principio de evitar conflictos de interés: la buena fe es un principio general del derecho; es el estado mental de honradez, de convicción respecto a la verdad. La buena fe en los negocios se manifiesta con el respeto a la integridad de los competidores, por atenerse al libre juego del mercado, porque no tergiversa los mensajes con campañas publicitarias agresivas. Hay buena fe en los negocios cuando no se defrauda o abusa de la confianza del otro, cuando se guarda fidelidad a la palabra dada y cuando ambas partes son colaboradoras y solidarias.

f) El principio de resolver con honradez los conflictos de intereses: las decisiones en el negocio y en la gestión empresarial deben ser independientes de los intereses personales y de los directivos.

g) El principio de respetar la integridad de las personas. 


\section{CÓDIGO DE CONDUCTA EMPRESARIAL}

Un código de conducta -CDC- recoge los valores y principios que deben guiar la gestión empresarial de cada organización. Un CDC es un documento, de carácter voluntario, que incluye un conjunto de principios, reglas 0 , en definitiva, buenas prácticas certificables por una tercera parte independiente, en cuya redacción se han tenido en consideración intereses de asociaciones de consumidores y usuarios, personas con discapacidad y otros colectivos afectados, que regulan, mejorando la normativa legal, contractual y postcontractual en lo que a la contratación se refiere, sin perjuicio de otras cuestiones como la publicidad interactiva, la seguridad, la privacidad, la usabilidad, la accesibilidad, la protección integral de menores de edad y otras conexas, cuya finalidad es la instauración y consolidación de la confianza del potencial consumidor y usuario ${ }^{27}$.

A partir de los años setenta comenzaron a surgir empresas que ponían por escrito los valores, principios y estilo propios de la cultura de la organización. A partir de los años noventa se generalizan los códigos. Y en el siglo XXI, con el incremento del uso de internet y del comercio electrónico, para las empresas que trabajan en este ámbito, el CDC tiene aún un interés mayor.

La autorregulación presenta la ventaja de hacer explícita la misión, propósito y razón de la organización, así como la visión de la misma. Las normas del código de conducta pretenden buscar la máxima calidad de los productos o servicios con el objetivo final de crear valor económico compatible con el desarrollo sostenible, es decir, fomenta la protección de los derechos de los interlocutores implicados en el negocio, la mejora del medioambiente y la cohesión social. De ahí que el código de conducta constituya un mecanismo para la promoción de los derechos humanos, laborales y medioambientales, así como de las medidas contra la corrupción.

Todo ello no significa que las empresas que dispongan de código sean necesariamente las mejores, en comparación con las que carecen del mismo. "El fin que se persigue y por el que se califica a una empresa de competitiva y excelente es la buena praxis en la gestión y la calidad de los compromisos en las relaciones laborales y de negocio" ${ }^{28}$. Como clarifica V. Labrada, "La función principal de los códigos es orientar las conductas de los miembros de la organización y sobre todo esclarecer la toma de decisiones ante conflictos y dilemas éticos que surgen en el desempeño del trabajo. Los valores que presiden el código facilitan a los interlocutores ser coherentes y conocer los criterios y prioridades del grupo por encima de cualquier convicción individual" 29 .

La Unión Europea ha recomendado a las empresas que los códigos de conducta empresarial contengan como normas mínimas de referencia los convenios de la Organización Internacional de Trabajo -OIT-, y las directrices de la Organización para la Cooperación y el Desarrollo Económico de multinacionales -OCDE-. También que los códigos de conducta deben incluir mecanismos de evaluación y control de su aplicación y un sistema de evaluación de la conformidad. Por último, que en la elaboración, aplicación y 
control de los mismos deben intervenir los interlocutores sociales, incluso países en desarrollo, y divulgar experiencias y prácticas correctas.

V. Labrada nos recuerda que hay que insistir en que la aplicación del código, en las organizaciones cuya dimensión territorial es internacional, debe extenderse a todos los niveles de la organización cualquiera que sea su ubicación geográfica, también en países en desarrollo, cuyo derecho laboral no alcance el nivel adquirido en los países desarrollados. En estos casos, el cumplimiento del código es una obligación que se adquiere con la autorregulación. siguientes:

En los códigos de conducta empresarial son valores comunes los

- La honestidad e integridad para actuar en todo momento de acuerdo con la visión y misión de la compañía y el servicio al cliente.

- La lealtad con las personas y proyectos, que se concreta en reconocer los errores para buscar la solución, así como en el esfuerzo para la mejora continua, el decir la verdad aunque pueda molestar, el interés en la realización del trabajo diario de acuerdo con los objetivos, admitiendo y comunicando los problemas que no se saben resolver.

- La austeridad, que requiere actuaciones dirigidas al ahorro y optimización de los recursos, evitando malgastar los que se tengan a disposición y valorándolos en todo momento.

- La integración en el trabajo de equipo. Dado que el éxito está por encima de cada trabajador, hay que orientar los propios intereses y esfuerzos hacia las necesidades, prioridades y proyectos del equipo, para lo que hay que cumplir los compromisos y motivar la mejora continua.

El apartado del código de conducta, que recoge los compromisos de los empleados, se ofrece para que lo firmen en el momento de su contratación.

Cada código recoge, junto a los valores corporativos, los principios que inspiran la gestión empresarial y el trato con los empleados, accionistas e inversores, con la Administración pública, los clientes, las comunidades locales, los proveedores y subcontratistas, la sociedad y el público en general, y el compromiso medioambiental.

\section{NUEVAS TECNOLOGÍAS Y CÓDIGO ÉTICOS INTERACTIVOS}

Las nuevas tecnologías y, especialmente Internet, plantean nuevos retos para las exigencias de la Ética ${ }^{30}$. La combinación de los protocolos convencionales y de reglas sociales era suficiente para gobernar Internet en sus inicios. El Derecho tenía entonces una función marginal: protegía los derechos de propiedad sobre el hardware de la red (el software era generalmente de libre disponibilidad) y los derechos fundamentales (libertad de palabra, de comunicación, de iniciativa privada) que permitían disfrutar de modo creativo las posibilidades que ofrecía la estructura de la red. Sin 
embargo, como subraya G. Sartor, la red va perdiendo progresivamente su "inocencia". El crecimiento de la red y la creciente diversidad de sus usuarios ponen en duda la idea misma de una comunidad de Internet, considerada como una comunidad de personas que participan en un proyecto común y aceptan normas comunes. Más que una comunidad, Internet aparece ser el "franmework for Utopia" descrito por R. Nozick, es decir un espacio vacío en el cual cada uno puede intentar construir, con quien esté disponible, una comunidad circunscrita que corresponde a los valores y a los intereses elegidos. Precisamente, el principal factor que ha determinado la pérdida de inocencia de la red consiste en su uso para actividades económicas. Esto ha introducido en la red nuevos y potentes actores, valores y prácticas, y ha determinado un cambio importante en su función social.

La colonización de Internet por parte del business ha determinado el fracaso de los mecanismos de autorregulación que funcionaban anteriormente. La definición de los estándar y de los protocolos, más que surgir de discusiones libres y competentes, según el juicio imparcial de los comités técnicocientíficos, tiende hoy a ser el resultado de batallas y compromisos entre estrategias comerciales en competencia. Incluso cuando en ocasiones resulta evidente que estándares diversos de los sostenidos por los leader del mercado podrían ofrecer mayores ventajas, los usuarios individuales son impotentes ${ }^{31}$.

Cada vez hay más empresas de la sociedad de la información y de comercio electrónico, que no pueden quedar al margen de unas exigencias éticas, al igual que tienen el resto de las empresas. A lo que hay que añadir que el factor de tratarse de comercio electrónico requiere un mayor grado de control pues la ocasión para el fraude, el engaño o la publicidad engañosa le hace ser más vulnerable. El comercio electrónico es una actividad contractual en auge con clara proyección de futuro. Sin embargo, hay un considerable elenco de fenómenos que impiden su efectivo despegue y consolidación, dificultando, de este modo, que dicha forma de contratación se convierta en una alternativa más atractiva que la adquisición de carácter presencial de esos servicios. Hay un punto de partida significativo: garantizar la accesibilidad plena y segura para todos los colectivos.

En España hay más de ocho millones de internautas compradores (13\% población), y esa cifra se incrementa cada año, debido a diversos factores entre los que indudablemente juegan un papel esencial los códigos de conducta reguladores de los diversos extremos que afectan al comercio electrónico y, por tanto, prestan especial atención a la accesibilidad y la usabilidad electrónica mejorando lo establecido en la propia legislación ${ }^{32}$.

Los presupuestos de un sistema de autorregulación en materia de comercio electrónico son los siguientes: a) acuerdo previo de todos los agentes que interactúan; b) Código de conducta -CDC-; c) Gestión por un tercero independiente; d) Sello de confianza acreditativo de la adhesión al CDC $^{33}$; e) Mecanismos extrajudiciales de resolución de conflictos.

En este contexto adquieren especial relevancia tres textos: 
1) DIRECTIVA 2000/31/CE del Parlamento Europeo y del Consejo, de 8 de junio de 2000, relativa a determinados aspectos jurídicos de los servicios de la sociedad de la información, en particular el comercio electrónico en el mercado interior (Directiva sobre el comercio electrónico) ${ }^{34}$;

2) La Ley 34/2002, de 11 de julio, de Servicios de la sociedad de la información y de comercio electrónico -LSSI-;

3) El Real Decreto 1163/2005, de 30 de noviembre, por el que se regula el distintivo público de confianza en los servicios de la sociedad de la información y de comercio electrónico, así como los requisitos y el procedimiento de concesión. Este real Decreto se aplica a las corporaciones, asociaciones u organizaciones comerciales, profesionales y de consumidores que adopten códigos de conducta destinados a regular las relaciones entre prestadores de servicios de la sociedad de la información y los consumidores y usuarios, cuando la adhesión a tales códigos conceda el derecho al uso y administración del "distintivo público de confianza en línea" (art.3).

\subsection{Sin detenernos en el análisis de la Directiva, comenzaremos a examinar la Ley 34/2002.}

En su Exposición de Motivos, explica lo qué se entiende por sociedad de la información, tomando como referencia la Directiva 2000/31/CE: «sociedad de la información» viene determinado por la extraordinaria expansión de las redes de telecomunicaciones y, en especial, de Internet como vehículo de transmisión e intercambio de todo tipo de información. Su incorporación a la vida económica y social ofrece innumerables ventajas, como la mejora de la eficiencia empresarial, el incremento de las posibilidades de elección de los usuarios y la aparición de nuevas fuentes de empleo ${ }^{35}$.

La Ley establece, asimismo, las obligaciones y responsabilidades de los prestadores de servicios que realicen actividades de intermediación como las de transmisión, copia, alojamiento y localización de datos en la red. En general, éstas imponen a dichos prestadores un deber de colaboración para impedir que determinados servicios o contenidos ilícitos se sigan divulgando. Las responsabilidades que pueden derivar del incumplimiento de estas normas no son sólo de orden administrativo, sino de tipo civil o penal, según los bienes jurídicos afectados y las normas que resulten aplicables. Destaca, por otra parte, en la Ley, su afán por proteger los intereses de los destinatarios de servicios, de forma que éstos puedan gozar de garantías suficientes a la hora de contratar un servicio o bien por Internet.

Con esta finalidad, la Ley impone a los prestadores de servicios la obligación de facilitar el acceso a sus datos de identificación a cuantos visiten su sitio en Internet; la de informar a los destinatarios sobre los precios que apliquen a sus servicios y la de permitir a éstos visualizar, imprimir y archivar las condiciones generales a que se someta, en su caso, el contrato. Cuando la contratación se efectúe con consumidores, el prestador de servicios deberá, además, guiarles durante el proceso de contratación, indicándoles los pasos que han de dar y la forma de corregir posibles errores en la introducción de 
datos, y confirmar la aceptación realizada una vez recibida. En lo que se refiere a las comunicaciones comerciales, la Ley establece que éstas deban identificarse como tales, y prohíbe su envío por correo electrónico u otras vías de comunicación electrónica equivalente, salvo que el destinatario haya prestado su consentimiento ${ }^{36}$.

Se favorece igualmente la celebración de contratos por vía electrónica, al afirmar la Ley, de acuerdo con el principio espiritualista que rige la perfección de los contratos en nuestro Derecho, la validez y eficacia del consentimiento prestado por vía electrónica, declarar que no es necesaria la admisión expresa de esta técnica para que el contrato surta efecto entre las partes, y asegurar la equivalencia entre los documentos en soporte papel y los documentos electrónicos a efectos del cumplimiento del requisito de «forma escrita» que figura en diversas leyes.

La Ley promueve la elaboración de códigos de conducta sobre las materias reguladas en esta Ley, al considerar que son un instrumento de autorregulación especialmente apto para adaptar los diversos preceptos de la Ley a las características específicas de cada sector

Por su sencillez, rapidez y comodidad para los usuarios, se potencia igualmente el recurso al arbitraje y a los procedimientos alternativos de resolución de conflictos que puedan crearse mediante códigos de conducta, para dirimir las disputas que puedan surgir en la contratación electrónica y en el uso de los demás servicios de la sociedad de la información. Se favorece, además, el uso de medios electrónicos en la tramitación de dichos procedimientos, respetando, en su caso, las normas que, sobre la utilización de dichos medios, establezca la normativa específica sobre arbitraje. La implantación de Internet y las nuevas tecnologías tropieza con algunas incertidumbres jurídicas, que es preciso aclarar con el establecimiento de un marco jurídico adecuado, que genere en todos los actores intervinientes la confianza necesaria para el empleo de este nuevo medio. conducta:

En el Capítulo III, artículo 18, se regulan, concretamente, los códigos de

1) Las Administraciones públicas impulsarán, a través de la coordinación y el asesoramiento, la elaboración y aplicación de códigos de conducta voluntarios, por parte de las corporaciones, asociaciones u organizaciones comerciales, profesionales y de consumidores, en las materias reguladas en esta Ley. La Administración General del Estado fomentará, en especial, la elaboración de códigos de conducta de ámbito comunitario o internacional. Los códigos de conducta podrán tratar, en particular, sobre los procedimientos para la detección y retirada de contenidos ilícitos y la protección de los destinatarios frente al envío por vía electrónica de comunicaciones comerciales no solicitadas, así como sobre los procedimientos extrajudiciales para la resolución de los conflictos que surjan por la prestación de los servicios de la sociedad de la información;

2) En la elaboración de dichos códigos, habrá de garantizarse la participación de las asociaciones de consumidores y usuarios y la de las organizaciones 
representativas de personas con discapacidades físicas o psíquicas, cuando afecten a sus respectivos intereses. Cuando su contenido pueda afectarles, los códigos de conducta tendrán especialmente en cuenta la protección de los menores y de la dignidad humana, pudiendo elaborarse, en caso necesario, códigos específicos sobre estas materias. Los poderes públicos estimularán, en particular, el establecimiento de criterios comunes acordados por la industria para la clasificación y etiquetado de contenidos y la adhesión de los prestadores a los mismos;

3) Los códigos de conducta a los que hacen referencia los apartados precedentes deberán ser accesibles por vía electrónica. Se fomentará su traducción a otras lenguas oficiales en la Comunidad Europea, con objeto de darles mayor difusión.

Por su parte, en el artículo 32 se regula la resolución extrajudicial de conflictos $^{37}$ :

\subsection{Mención especial hay que hacer a las medidas específicas recogidas en el Código ético de publicidad interactiva y comercio por Internet.}

De los distintos códigos de conducta existentes ${ }^{38}$ nos vamos a centrar en el Código ético de comercio electrónico y publicidad interactiva y comercio por Internet, por ser el código específico que más vinculación tiene con el tema que estamos tratando ${ }^{39}$. Mediante el citado código, las entidades manifestaron su "serio compromiso por crear y sostener, en el marco de la defensa del ejercicio de la ética y la deontología profesional, un sistema integral de autorregulación relativo a la publicidad y a las transacciones comerciales con los consumidores en los medios electrónicos de comunicación a distancia" (Preámbulo). Entre las distintas normas que recoge trata especialmente los ámbitos de las comunicaciones comerciales (Título II) ${ }^{40}$ y comercio electrónico (Título III $)^{41}$, sin olvidar la necesaria atención que merece la protección de datos personales en el desarrollo de ambas actividades (Título IV) ${ }^{42}$, así como la protección y la salvaguarda de los menores (Título $\mathrm{V})^{43}$ y la accesibilidad y usabilidad (Título VI) ${ }^{44}$. Asimismo, establece las normas de aplicación del código, haciendo especial referencia a la resolución extrajudicial de controversias (Título VII) ${ }^{45}$ y la colaboración con las autoridades (Título VIII).

En definitiva, los Códigos de Conducta, o Códigos de buenas prácticas o Códigos éticos, comprenden una serie de requerimientos mínimos o reglas que toda empresa que actúe en la Red debe cumplir para garantizar la seguridad en las transacciones mercantiles y la protección de los derechos de los usuarios que visitan esos sitios web.

- Las empresas que quieren obtener un sello de confianza deben adherirse a estos códigos, y se comprometen a cumplirlos voluntariamente.

- Los códigos

- ofrecen unas garantías concretas que mejoran o incrementan las reconocidas por el ordenamiento jurídico.

suponen la asunción de unos compromisos específicos, de distinta naturaleza y que dependen de la entidad que los promueve. 
- Los CDC más habituales ofrecen más garantías como la existencia de sistemas extrajudiciales de resolución de conflictos y compromisos adicionales relacionados con la integración, la accesibilidad para discapacitados o personas de avanzada edad, medidas que protegen los derechos de los menores y la dignidad de las personas, e instrucciones sobre sistemas de filtrado, procedimientos de autocontrol, etc. Incluyen procedimientos independientes para valorar y comprobar que los prestadores de servicios adheridos cumplen las obligaciones asumidas. Para ello establecen también un régimen sancionador adecuado, eficaz y disuasorio. Los CDC que pretendan obtener el "Distintivo Público de confianza en línea" (art.7) deberán establecer, como medio de solución de controversias entre los prestadores de servicios y los consumidores y usuarios el sistema arbitral de consumo u otro sistema de resolución extrajudicial de conflictos que figure en la lista que publica la Comisión Europea sobre sistemas alternativos de resolución de conflictos con consumidores.

\section{DISTINTIVO PÚBLICO DE CONFIANZA EN LÍNEA}

La Disposición Final Octava, de la Ley 34/2002, ha sido desarrollada a través del Real Decreto 292/2004, de 20 de febrero, por el que se crea el Distintivo Público de Confianza en Línea, para los mecanismos de autorregulación solventes, creíbles y eficaces en el ámbito de los servicios de la sociedad de la información. Posteriormente, el Real Decreto 1163/2005, de 30 de septiembre, deroga el anterior Real Decreto 292/2004 ${ }^{46}$.

Es un sello que se otorga a los prestadores de servicios que se encuentren dentro del marco normativo de la Ley de Servicios de la Sociedad de la Información y estén adheridos a un código de confianza aprobado por el Instituto Nacional de Consumo. La empresa a la que se el concede Puede incorporar un logotipo o marca tanto gráficamente como por su denominación en todas sus manifestaciones internas y externas, incluida la publicidad. El distintivo pretende servir de guía para que los consumidores y usuarios puedan discernir, dentro del conjunto de sellos y códigos, aquellos que incorporan garantías y un nivel de protección adicional de sus derechos, al estar respaldados por el Instituto Nacional de Consumo.

Los códigos de conducta deben respetar la legalidad vigente e incluir, como mínimo, con suficiente grado de precisión (art.4.2):

a) Las garantías concretas que ofrecen a los consumidores y usuarios que mejoren o incrementen las reconocidas por el ordenamiento jurídico

b) Un sistema de resolución extrajudicial de conflictos (de entre los previstos en el artículo 7)

c) Los compromisos específicos que asumen los prestadores de servicios adheridos en relación con los problemas concretos, planteados a los consumidores y usuarios del sector, identificados según la información de los promotores del código y la que, al efecto, les faciliten, las 
asociaciones de consumidores y las Administraciones públicas sobre las reclamaciones presentadas por los consumidores y usuarios.

d) El ámbito de las actividades del prestador de servicios sometidas al código que, al menos, englobará alguna de las siguientes áreas: las comunicaciones comerciales 0 la información precontractual, la contratación y los procedimientos de solución de quejas 0 reclamaciones, cuando estos sean distintos de los sistemas de resolución extrajudicial de conflictos a los que se refiere el artículo 7.

Sin perjuicio de cualquier otro compromiso que puedan establecer las entidades promotoras de los códigos de conducta regulados por el citado Real Decreto, estos podrán contener previsiones específicas (art.5) sobre:

a) El grado de accesibilidad a los contenidos de los consumidores y usuarios que tengan alguna discapacidad 0 de edad avanzada, conforme a los criterios de accesibilidad generalmente reconocidos

b) Las medidas concretas adoptadas en materia de protección de los menores y de respeto a la dignidad humana y a los valores y derechos constitucionalmente reconocidos.

c) La adhesión a códigos de conducta sobre clasificación y etiquetado de contenidos.

d) Las instrucciones sobre los sistemas de filtrado de contenidos utilizables en las relaciones con los prestadores de servicios.

e) Los procedimientos previstos para comprobar que los prestadores de servicios reúnen las condiciones exigidas para la adhesión al código de conducta y la utilización del distintivo.

Los códigos de conducta que pretendan obtener el "distintivo público de confianza en línea" deberán establecer, como medio de solución de controversias entre los prestadores de servicios y los consumidores y usuarios, el sistema arbitral de consumo u otro sistema de resolución extrajudicial de conflictos que figure en la lista que publica la Comisión Europea sobre sistemas alternativos de resolución de conflictos con consumidores y que respete los principios establecidos por la normativa comunitaria a este respecto (art.7).

Los códigos de conducta deberán incluir procedimientos de evaluación independientes para comprobar el cumplimiento de las obligaciones asumidas por los prestadores de servicios adheridos, y establecer un régimen sancionador adecuado, eficaz y disuasorio ${ }^{47}$.

El otorgamiento del distintivo se lleva a cabo de la siguiente manera: Las entidades promotoras de los códigos de conducta regulados en este Real Decreto presentarán su solicitud ante el órgano administrativo competente para la concesión y retirada del distintivo, a la que acompañarán de una copia del código, de la documentación acreditativa de la participación del Consejo de Consumidores y Usuarios y, en su caso, de haberse comunicado el proyecto de código a la Comisión Europea. Asimismo, deberán aportar la documentación relativa a la adhesión de los prestadores de servicios que lo hayan suscrito al sistema extrajudicial de resolución de conflictos que se prevea en el código (art.11.1). Las resoluciones que se dicten en este procedimiento deberán ser 
motivadas y se publicarán en el diario oficial de la comunidad autónoma competente (art.11.3).

El derecho a la utilización y administración del "distintivo público de confianza en línea" podrá ser retirado si las entidades promotoras de los códigos de conducta reconocidos incumplen las obligaciones establecidas en el citado Real Decreto. La retirada del derecho a la utilización y administración del "distintivo público de confianza en línea" a una entidad promotora implicará la imposibilidad de su utilización por parte de los prestadores de servicios adheridos al código de conducta. Asimismo, ante la inactividad de la entidad promotora y sin perjuicio de las medidas que pudieran adoptarse frente a ella por tal causa, podrá retirarse directamente el uso del distintivo a los prestadores de servicios que incumplan manifiesta y reiteradamente el código de conducta cuya adhesión les confiera tal derecho (art.12) ${ }^{48}$.

Los sellos son, generalmente, modos de autorregulación que pueden adoptar diversas formas. Entre los sellos existen algunas diferencias que deben tenerse en cuenta respecto al nivel de compromiso que supone su adhesión para la empresa, no sólo en cuanto a su contenido sino también en cuanto al procedimiento para su concesión.

- Por ejemplo, un sello concedido tras un riguroso procedimiento de auditoría, dirigido a la comprobación del cumplimiento efectivo, por parte de una entidad o empresa, de un estricto código de conducta, es diverso de un sello que se concede por la adhesión a una norma pero que no requiere una supervisión o certificación. Los tipos de sellos son: a) Sellos de confianza; b) Sellos de adecuación a buscadores; c) Sellos de seguridad; d) Sellos de Compromiso con la LSSI. En general, los sellos de confianza suponen un mayor grado de implicación de la empresa, al tener que cumplir más requerimientos para su obtención. Lo sellos implican unos requerimientos y condiciones establecidas previamente en un código de conducta o ético elaborado por la entidad promotora del sello y para cuya obtención suele ser necesario un completo proceso de auditoría.

Los principales sellos son: 1) Sello de Confianza On Line Promovido por la Asociación para la Autorregulación de la Comunicación Comercial (AUTOCONTROL) y la Asociación Española de Comercio Electrónico y Marketing Relacional (AECEM).www.confianzaonline.es; 2) Sello de Calidad AGACE. Promovido por la Asociación para la promoción de las tecnologías de la Información y el Comercio Electrónico (APTICE).www.agace.org; 3) Sello OptimaWeb (Código de Conducta de Confianza On Line y E-Commerce) Promovido por la Asociación para el fomento del Comercio Electrónico Empresarial (ANETCOM) www.optimaweb.anetcom.es.

Pero actualmente sólo existen tres códigos de conducta o sellos de confianza que cuentan con el "Distintivo Público de Confianza en Línea" reconocido por el Instituto Nacional del Consumo y son los siguientes: aprobados por el Instituto Nacional de Consumo:

1.El código de confianza Online y E-Commerce Óptima Web, promovido por ANETCOM; 
2. El código de conducta APTICE de la Asociación para la Promoción de las Tecnologías de la Información y el Comercio Electrónico (APTICE) 3. El código de conducta Confianza On Line, promovido por la Asociación para la Autorregulación de la Comunicación Comercial (AUTOCONTROL) y la Asociación Española de Comercio Electrónico y Marketing Relacional (AECEM).

Sin embargo, prácticamente hay un monopolio del distintivo por parte de la asociación promotora del sello (http://www.confianzaonline.com) ${ }^{49}$, ya que cuenta con numerosas adhesiones y cobra por ello. Confianza Online tiene el objetivo de fomentar el uso y la navegación de forma tranquila y segura en Internet y los medios digitales ${ }^{50}$.

En 2005, confianza online integró su imagen del Sello de confianza online con la del Distintivo Público de Confianza en Línea, debido a su concesión por el Gobierno el mes de julio de ese año ${ }^{51}$.

Adherirse a un sello de confianza conlleva generalmente unos costes económicos que fija la entidad promotora y dependen, en general, del trabajo que suponga la evaluación y auditoría que significa su concesión. El coste se fija, a menudo, en función del tipo de empresa, la complejidad de la actividad de comercio electrónico y de su facturación anual. En general el coste de adhesión se paga el primer año y, a partir de ahí, se abona una cuota anual de menor cuantía. Cuando un sello caduca y se quiere renovar, se debe pagar una cuota de renovación que comporta la realización de una nueva auditoría completa.

Hay una comprobación de los códigos de conducta: La empresa tiene el compromiso de estar sujeta a un proceso continuo de evaluación de que se cumple las condiciones para poder ostentar ese sello o marca. Esta evaluación se realiza mediante un sistema de auditorías, elaboradas por especialistas dependientes de la entidad certificadora. Las auditorías evalúan el cumplimiento por parte de la empresa de los principios y estándares de calidad establecidos en el código de conducta del sello. Gran parte del análisis se basa en la web: sus aspectos técnicos, de seguridad informática y de cumplimiento de requisitos legales del comercio electrónico. Los resultados de las auditorías se reflejarán en informes de carácter confidencial (informes de auditoría) en los que se indican, en su caso, las no conformidades detectadas y las acciones correctoras necesarias. El no cumplimiento de estas medidas en unos determinados plazos puede dar lugar a la no obtención o pérdida del sello.

\section{A MODO DE CONCLUSIÓN}

Si bien una certificación de calidad es interesante también hay que considerar quién está detrás de esa certificación. Las críticas sobre algunos sellos de confianza son notorias ${ }^{52}$. Asimismo, hay que tener presente, para los usuarios, que este sello solo indica que la pagina web que lo tiene cumple con la ley pero esto no es ninguna garantía de que no tenga condiciones de compra 
abusivas, de que trate sus datos con la seguridad debida o de que cumplan realmente las condiciones anunciadas.

Con todo, un sello de confianza constituye un paso más en orden a garantizar la seguridad al usuario. $Y$ todo ello revestido de un tinte ético que ayudará a prestigiar más a la propia empresa y a los negocios que lleve a cabo, bien sea utilizando internet como por otras vías. La reivindicación de la ética y de los valores reviste de un plus de legitimidad a las empresas.

\title{
FROM ETHICAL CODE OF ENTERPRISES TO THE CODES OF CONDUCT AND SYMBOL OF TRUST ON E-TRADE
}

\begin{abstract}
In the conpany's activities and business, along with procurement strategy, sales or profits, it is necessary to introduce moral standarts. We must discern what can bring business experience to the business ethics at the same time we must also know how to value it can bring ethic to the proper functioning of the company. Ethics requires companies to asses the quality of the conduct with the objectives are achieved, if the conduct is moral or not, whether fair or unfair. The protocols of good pratice and business conduct codes allow a better interaction between business and ethics. On the other hand, new technologies, especially the internet, pose new challenges to the demands of ethics. The colonization of the internet by the business has given the failure regulatory mechanisms that worked previously. Hence it becomes necessary to design interactive ethical codes, among wich include the Code of Ethics and Trade Interactive Advertising on the Internet and the Public Trust Distinctive Online. This dye coated ethical prestige more to help the company and the business conducted. The claim of ethics and values plus takes on a legitimacy to enterprises.
\end{abstract}

\section{NOTAS}

1. possui doutorado pela Universidad de Valladolid (1987). Atualmente é Professora Titular da Universidad de Burgos. Tem experiência na área de Direito.

2. La ablación del clítoris puede ser una práctica moral (una "costumbre") ampliamente aceptada en una determinada cultura, pero para que fuera ética habría que dar, además, argumentos públicamente debatibles en su favor (DOMENĖCH, A., "Ética pública y control democrático. La función de la ética pública en el funcionamiento de la democracia" en Ética pública. Desafíos y propuestas, en IZQUIERDO, A. y LAGO, S. (Edts.), Barcelona, Edicións Bellaterra, 2008, p.11).

3. VELASQUEZ, M.G., Ética en los negocios. Conceptos y casos, 6aㅡ. ed., México, Pearson, 2006, pp.9-10.

4. DIEGO, O., "Fortaleza ética en gobernantes y funcionarios de la Administración pública" en Revista Ética Administrativa, IAP del Estado de Quintana Roo, México, 2004, pp.3-28.

5. Cfr. OlleRO, A., "Responsabilidades políticas y razón de Estado", en Papeles de la Fundación para el análisis y los estudios sociales, núm.31, pp.19 y ss.

6. "Son modelos de conducta o de comportamiento, estrategias de felicidad que forman contenidos de planes de vida que se ofrecen a los posibles destinatarios del mismo. Puede

REVISTA DO DIREITO UNISC, SANTA CRUZ DO SUL No 35|P. 101-129| JAN-JUN 2011 
ser obra de uno mismo o asumida desde una iglesia o concepción filosófica. Estos destinatarios son las personas individuales y es necesaria la aceptación de cada uno para que se pueda hablar de moralidad privada" ("Ética pública-ética privada", en Anuario de Filosofía del Derecho XIV, Madrid, pp.541-543. Vid. también, del mismo autor, Diez lecciones sobre Ética, Poder y Derecho, Madrid, Dykinson, 2010).

En el contexto español fue Gregorio Peces-Barba quien a mediados de la década de los noventa del siglo pasado presentó su propuesta de Ética pública como la superación de la tradicional dicotomía entre derecho y moral, incorporando al primero una dimensión de moralidad cuyo elemento básico y superior será la justicia.

7. "Sin espacio público que facilite la existencia de ofertas de moralidad plurales, y sin posibilidad de que las personas acepten libremente o creen libremente un proyecto de ética privada o un plan de vida, no hay moralidad pública o ésta carece de sentido [...] Su finalidad es que todos y cada uno de los ciudadanos, en la mayor medida posible, estén en condiciones de desarrollar plenamente los rasgos de su dignidad autónoma. Los destinatarios y a la vez impulsores de la ética pública son las autoridades, los poderes públicos, los operadores jurídicos -legisladores, jueces y funcionarios- y también cada persona individual como ciudadano y los grupos que se forman por estos individuos" (PECES-BARBA, G., Diez lecciones sobre Ética, Poder y Derecho, cit., pp.56-57).

8. Como apunta J. Rodríguez Alba: "[...] frente al 'desconcierto del mundo', generado acaso por el 'excesivo afán de lucro', el 'egoísmo creciente', la 'avaricia', por la 'pérdida de virtudes', etc., debemos rescatar el lenguaje de la ética (y de la ética de las virtudes en tanto ética práctica)". Sólo ésta permitirá "afianzar virtudes para recomponer el maltrecho tejido de la sociedad" (RODRÍGUEZ ALBA, J., "Ideología y política en la ética pública. La cuestión del Estado ético" Ética y servicio público, en PEÑA, L., AUSíN, T. y DIEGO, O. (edts.), Madrid, Plaza y Valdés editores, 2010, p.272).

9. Las organizaciones de negocios son instituciones principalmente económicas a través de las cuales las personas de las sociedades modernas realizan las tareas de producir y distribuir bienes y servicios. Las organizaciones proporcionan las estructuras fundamentales $y$, dentro de ellas, los miembros de la sociedad combinan sus escasos recursos: tierra, mano de obra, capital y tecnología, para convertirlos en bienes utilizables; también proporcionan los canales por lo que estos bienes se reparten en forma de productos para el consumidor, salarios de empleados, rendimientos para los inversores e impuestos para el gobierno. Al analizar los aspectos éticos originados por una decisión o caso particular es útil ordenar los aspectos según si son sistémicos, corporativos o individuales. Si una compañía intenta manejar un aspecto sistémico -como la cultura de un gobierno que permite el soborno-, entonces el aspecto debe manejarse a nivel sistémico; es decir, a través de las acciones coordinadas de muchos grupos sociales; por otro lado, los aspectos éticos corporativos se podrían resolver a través de soluciones corporativas o de la compañía: por ejemplo, si la cultura de la compañía fomenta acciones morales erróneas, entonces, cambiar esa cultura requiere la cooperación de las personas que constituyen la compañía. Finalmente, los aspectos éticos individuales deben resolverse mediante decisiones individuales -e incluso, mediante la transformación individual-. (VELASQUEZ, M.G., Ética en los negocios, cit., p.14).

10. LABRADA RUBIO, V., Ética en los negocios, Madrid, ESIS Editorial, 2010, p.100.

11. Factores como la corrupción, la subsistencia de la pobreza y la marginación, en el marco de la sociedad capitalista, han aumentado el interés por la reflexión ética en economía. G. Peces-Barba, a este respecto, ha diferenciado cuatro periodos:

a) En los albores de la modernidad estamos todavía en la economía moral, es decir, de la subordinación de la economía a la teología católica y a su concepción moral;

b) A partir de A. Smith encontramos un signo de secularización, especialmente con la separación y distinción entre la moral y la economía;

c) La influencia de la economía aumenta tanto que sus reglas (especialmente las del mercado) se convierten en moralidad por encima de las propias reglas morales, tanto de la ética pública como las de la privada. Es la economía como moralidad;

d) A partir de la Segunda Guerra Mundial aumenta la preocupación ética por la economía, y también la preocupación económica por la Ética. Estas corrientes se interesan por las dimensiones morales de la economía, al servicio, en última instancia, de la dignidad humana. Se incide en la ética pública y en el estudio de los problemas sobre la corrupción (PECES-BARBA, Gregorio, Diez lecciones sobre Ética, Poder y Derecho, Madrid, Dykinson, 2010, pp.412-413). 
$\operatorname{COM}(2001) 366, \mathrm{n} \div 65$

No vamos a detenernos en el gobierno corporativo. Nos limitamos a hacer una breve referencia. Surge de la necesidad de superar los problemas que plantea la separación entre la propiedad y la gestión en las grandes sociedades que cotizan en Bolsa. Las sociedades que cotizan en bolsa han ido incorporando códigos y autorregulaciones que favorecen el llamado buen gobierno de las mismas. Estos códigos introducen en los gobiernos de las sociedades medidas que, más allá del cumplimiento de la ley, favorezcan la transparencia y la independencia en la gestión de las sociedades. El consejo de administración de una sociedad que pretenda una gestión responsable, además de organizarse según el código del buen gobierno, debe integrar en la gestión los fines y bienes que corporativamente persiguen y las buenas prácticas que han de cultivar sus miembros. El principio de legalidad, al igual que en los códigos de conducta empresarial, constituye criterio previo a toda autorregulación y obliga al cumplimiento y aplicación de las leyes generales del Estado sobre las sociedades mercantiles, así como las normas imperativas de instituciones como la CNMV. Tras los últimos escándalos financieros, buena parte de la autorregulación del gobierno corporativo de las sociedades que cotizan en bolsa ha sido desplazada por la intervención legislativa. La Ley de Transparencia, en el caso español, incorpora a la legislación mercantil las principales normas de buen gobierno corporativo con el fin de recuperar la confianza de los inversores en el mercado de valores (Cfr. LABRADA RUBIO. V., Etica en los negocios, cit., pp.230-233).

14. Cfr. OTERO PARGA, M., "La Ética del mediador", en Mediación y resolución de conflictos: técnicas y ámbitos, en SOLETO MUÑOZ, H. (Directora), Madrid, Tecnos, 2011, p.88.

15. Ibidem.

16. En Estados Unidos la medicina fue pionera en los años 60 en establecer unas normas éticas de referencia para el ejercicio de la profesión. El primer texto de ética médica en dicho país es de 1966. Después del asunto Watergate de 1974, los profesionales del derecho elaboraron su propio código deontológico; posteriormente son los ingenieros el colectivo que opta por la autorregulación, y es en los años 80 cuando la Ética, expresada y formulada en códigos de conducta, llega al mundo de la empresa. En Estados Unidos actualmente se imparten más de 500 cursos de Ética de empresa (LABRADA RUBIO, V., Ética en los negocios, cit., p.108).

17. Las virtudes de la prudencia, de la justicia, de la fortaleza y la templanza, que Aristóteles describe en la Ética a Nicómaco, en el siglo IV a.C., son virtudes que en la antropología actual se han consolidado como guías de la conducta humana. La virtud de la prudencia es clave para quienes dirigen y ejercen el poder. Asimismo, la obra El arte de la prudencia de Baltasar Gracián, publicado en 1647, ha sido útil en las Escuelas de Negocios por las recomendaciones que aporta para la práctica de esta virtud: vencerse a sí mismo para que los demás te respeten (157); dejarse ayudar: necesitamos ayuda de los demás, nunca lo podemos hacer solos todo (167); saber estimar: el prudente saca lo bueno de cada uno y saca partido de las cualidades de sus subordinados (195); saber olvidar: el prudente debe olvidarse de lo hecho y avanzar (262); saber usar el desliz: el prudente reacciona ingeniosamente ante un error (873); saber hacer la evaluación: aquel que se conoce a sí mismo y conoce a los demás, domina y ordena su entorno (291); arte para ser dichoso; elegir bien los medios para conseguir los fines es una actitud inteligente del prudente (21) (GRACIÁN, B., El arte de la prudencia, Madrid, Temas de Hoy, 1993).

18. El Dr. D. Eusebio Fernández García es el Director de la citada Cátedra.

19. RODRÍGUEZ ALBA, Jaime, op.cit., p.271, nota 1.

20. Cfr. LABRADA RUBIO, Valle, Ética en los negocios, cit., p.119.

21. LABRADA RUBIO, V., Ética en los negocios, cit., p. 122.

22. LABRADA RUBIO, V., Ética en los negocios, cit., p. 195.

23. La cooperación al mal admite diferentes niveles dependiendo del tipo de colaboración que se efectúe. Se denomina cooperación formal cuando no hay conocimiento ni consentimiento de la acción corrupta. En la cooperación material sí hay conocimiento y consentimiento. Se llama cooperación directa cuando se proporciona un medio con relación necesaria con la acción incorrecta, y la cooperación indirecta cuando no hay tal relación. Desde otra perspectiva y en función de la proximidad del cooperante con el resultado ilícito, la cooperación también puede ser próxima si hay cercanía, o remota cuando no la hay.

24. LABRADA RUBIO, V., Ética en los negocios, cit., p. 197.

25. Seguimos la clasificación que presenta V. Labrada Rubio (Ibidem, p.198).

26. Seguimos la clasificación que presenta V. Labrada Rubio (Ibidem, pp. 198-207). 
27. Vid. GOÑI SEIN, José Luis, Ética empresarial y código de conducta. Madrid, La Ley.

28. LABRADA RUBIO, V., Ética en los negocios, cit., p. 215.

29. Ibidem.

30. El desarrollo de la red se ha visto influido por cuatro inspiraciones ideales: a) La cultura técnico-meritocrática, caracterizada por los valores del descubrimiento tecnológico, por la competencia y la división del conocimiento; b) La cultura hacker, que une a los valores técnico-meritocráticos los aspectos de la creatividad y de la cooperación; c) La cultura virtual-comunitaria, caracterizada por los valores de la comunicación, asociación y autoorganización; d) La cultura emprenditorial, basada en los valores del dinero, del trabajo y del consumo (Cfr. SARTOR, G., "Il diritto della rete globale", en Ciberspazio e diritto, 4, 2003, p.9).

31. SARTOR, G., "Il diritto della rete globale", en Ciberspazio e diritto, cit., p.11.

32. El objetivo es que una web pueda ser accesible y usada por el mayor número posible de personas, con independencia tanto de las limitaciones del propio usuario como de las que derivan del contexto desde el que el usuario accede.

33. A la hora de proporcionar y fomentar la confianza por parte de los potenciales clientes y usuarios, es importante el papel que juegan los sellos de confianza, que en realidad, no son más que la manifestación gráfica de los códigos de conducta. Por parte de los compradores virtuales cada vez es mayor el conocimiento y la valorización de los sellos de confianza, a los que nos referiremos en las páginas siguientes.

34. No vamos a extendernos en el análisis de esta directiva. Destacamos únicamente algunos puntos relevantes en cuanto al tema que nos ocupa. Así, desde sus considerandos iniciales establece:

(18)Los servicios de la sociedad de la información cubren una amplia variedad de actividades económicas que se desarrollan en línea; dichas actividades en particular consisten en la venta de mercancías en línea;

(34) Todos los Estados miembros deben ajustar su legislación en cuanto a los requisitos que puedan entorpecer la celebración de contratos por vía electrónica (registro de contratos, efecto jurídico de la firma electrónica, etc.). El resultado de dicho ajuste debería hacer posibles la celebración de contratos por vía electrónica.

(51) Corresponderá a cada Estado miembro, llegado el caso, ajustar aquellas disposiciones de su legislación que puedan entorpecer la utilización de los mecanismos de solución extrajudicial de conflictos por vías electrónicas adecuadas. El resultado de dicho ajuste debe hacer posible el funcionamiento de tales mecanismos de forma real y efectiva, tanto de derecho como de hecho, incluso en situaciones transfronterizas.

(52) [...] Los Estados miembros estudiarán la necesidad de ofrecer acceso a los procedimientos judiciales por los medios electrónicos adecuados.

En su artículo 16 regula los Códigos de conducta, estableciendo que los Estados miembro y la Comisión fomentarán la elaboración de códigos de conducta a nivel comunitario, a través de asociaciones u organizaciones comerciales, profesionales o de consumidores - con el fin de contribuir a que se apliquen correctamente los artículos 5 a 15-. En su artículo 17 regula la solución extrajudicial de conflictos: "Los Estados miembros velarán por que, en caso de desacuerdo entre un prestador de servicios de la sociedad de la información y el destinatario del servicio, su legislación no obstaculice la utilización de los mecanismos de solución extrajudicial, existentes con arreglo a la legislación nacional para la solución de litigios, incluso utilizando vías electrónicas adecuadas (art.17.1).

35. Se acoge, en la Ley, un concepto amplio de «servicios de la sociedad de la información», que engloba, además de la contratación de bienes y servicios por vía electrónica, el suministro de información por dicho medio (como el que efectúan los periódicos o revistas que pueden encontrarse en la red), las actividades de intermediación relativas a la provisión de acceso a la red, la transmisión de datos por redes de telecomunicaciones, la realización de copia temporal de las páginas de Internet solicitadas por los usuarios, el alojamiento en los propios servidores de información, servicios o aplicaciones facilitados por otros o la provisión de instrumentos de búsqueda o de enlaces a otros sitios de Internet, así como cualquier otro servicio que se preste a petición individual de los usuarios (descarga de archivos de video o audio), siempre que represente una actividad económica para el prestador. Estos servicios son ofrecidos por los operadores de telecomunicaciones, los proveedores de acceso a Internet, los portales, los motores de búsqueda o cualquier otro sujeto que disponga de un sitio en Internet a través del que realice alguna de las actividades indicadas, incluido el comercio electrónico (Exposición de Motivos de la Ley 34/200). 
36. Exposición de Motivos, III).

37. La regulación es la siguiente: 1 . El prestador y el destinatario de servicios de la sociedad de la información podrán someter sus conflictos a los arbitrajes previstos en la legislación de arbitraje y de defensa de los consumidores y usuarios, y a los procedimientos de resolución extrajudicial de conflictos que se instauren por medio de códigos de conducta u otros instrumentos de autorregulación. 2. En los procedimientos de resolución extrajudicial de conflictos a que hace referencia el apartado anterior, podrá hacerse uso de medios electrónicos, en los términos que establezca su norma.

38. Entre otros: Código de Conducta publicitaria de Autocontrol, Código ético de publicidad en cine, Código deontológico para la publicidad Infantil, Código general de conducta publicitaria de las instituciones de inversión colectiva y fondos de pensiones asociados a INVERCO, ICC International Code of Adversating Practice, en http://www.aap.es

39. El Código ético de comercio electrónico y publicidad interactiva, aprobado en 2002, es el resultado de la adaptación de dos códigos anteriores: el "Código de protección de datos de Internet" y el "Código ético de publicidad en Internet", a los nuevos avances y a los preceptos de la Directiva de comercio electrónico y a la Ley de servicios de la sociedad de la información y comercio electrónico.

40. Así por ejemplo, en cuanto al ámbito de la publicidad, establece medidas de protección al consumidor: 1) El deber de identificación del mensaje publicitario; 2) La prohibición de correo electrónico no solicitado; 3) El deber de información previo, informando sobre: a) Precio de compra completo, con referencia a los impuestos aplicables e incluidos, así como la moneda, la modalidad de pago, el franqueo y los portes; b) Plazo de validez de la oferta, si se tratase de una oferta promocional; c) Términos, condiciones y formas de pago; d) Las diferentes formas de entrega o ejecución que puedan existir de los productos 0 servicios contratados; e) Características de los bienes o servicios y, en su caso, las condiciones necesarias para su utilización; f) Existencia o inexistencia de costes adicionales; g) Condiciones para el ejercicio del derecho de desistimiento y devolución; h) Garantías aplicables a la adquisición del producto o servicio; i) Lugar y forma de presentación de posibles reclamaciones; j) Domicilio del oferente a efectos legales: Contenido mínimo de información al que se refiere igualmente la Ley de ordenación del comercio minorista, aplicable al comercio electrónico como ya comentamos, por lo que no podemos considerar en este sentido que exista novedad alguna; 4) La prohibición de impedir la libre y normal navegación del usuario en Internet.

41. Se hace especial hincapié en que las actividades de contratación de bienes o servicios con consumidores de medios electrónicos de comunicación a distancia deben respetar el principio de legalidad (art.14). Se establecen unas obligaciones previas al inicio del procedimiento de contratación, tales como poner de forma clara, comprensiva e inequívoca los pasos a seguir para la adquisición del bien o la contratación de servicio ofrecido. Asimismo, el oferente deberá facilitar al consumidor el acceso, al menos a través de su página web o sitio web, de manera visible, de extremos tales como: a) Precio completo, con referencia a los impuestos aplicables, así como los gastos de franqueo, descuentos y otros; b) Plazo de vigencia de la oferta; c) Términos, condiciones y formas de pago, incluyendo en su caso opciones de crédito; d) Diferentes modalidades de entrega o de ejecución que puedan existir de los productos o servicios contratados; e) Existencia o no del derecho de desistimiento, derechos de cancelación, etc.; g) Garantías aplicables al producto; h) Lugar y forma de presentación de posibles reclamaciones, incluyendo los procedimientos de resolución extrajudicial de conflictos; i) Nombre, razón social y domicilio del oferente; j) Lengua o lenguas en las que podrá formalizarse el contrato. También se establecen unas obligaciones de información posteriores a la celebración del contrato, plazos de entrega, desistimiento y devolución, reparación y sustitución, servicio de atención al cliente, seguridad y medios de pago y ofertas públicas de contratación electrónica entre empresas.

42. Las entidades adheridas que realicen publicidad 0 transacciones contractuales con consumidores a través de medios electrónicos de comunicación a distancia deberán respetar la normativa vigente en materia de protección de datos personales (art.23).Estos datos sólo podrán obtenerse para su tratamiento cuando sean adecuados, pertinentes y no excesivos en relación con el ámbito y las finalidades determinadas, explícitas y legítimas para las que se hayan obtenido. Las entidades adheridas deberían respetar la privacidad de los usuarios, así como asegurar el secreto y seguridad de los datos personales, adoptando para ello las medidas técnicas y organizativas necesarias. Se regula la obtención de los datos, el tratamiento para finalidades distintas del contrato, el tratamiento de datos 
obtenidos de fuentes accesibles al público, el tratamiento de datos para actividades de publicidad y prospección comercial, transferencias internacionales de datos, consentimiento del titular, ejercicio de derechos, uso de cookies y dispositivos similares, captación de datos personales en grupos de noticias, foros, charlas (chats) y similares con finalidad publicitaria, seguridad y protección de datos.

43. La publicidad difundida en medios electrónicos de comunicación a distancia no deberá perjudicar moral o físicamente a los menores y tendrá que respetar principios tales como: a) Deberá identificar los contenidos dirigidos únicamente a adultos; b) No deberá incitar a menores a la compra de un producto o servicio, explotando su inexperiencia o incredulidad; c) En ningún caso deberá explotar la confianza de los niños en sus padres o tutores, profesores u otras personas; d) No deberá presentar a los niños en situaciones peligrosas (art.34). Se regulan los contenidos sobre protección de menores, el tratamiento de datos de menores y la promoción de la protección de los menores.

44. Las entidades adheridas, en la medida en que resulte aplicable legalmente, apoyarán las medidas dirigidas a adaptar sus sitios web a los protocolos de accesibilidad generalmente reconocidos con el objetivo de hacer efectiva la navegación de personas con discapacidad y mayores. Asimismo, en la medida en que resulte aplicable legalmente, las entidades adheridas procurarán tener en cuenta los criterios de usabilidad para que los usuarios puedan navegar de la forma más fácil, cómoda e intuitiva posible (art.38.1).

45. El artículo 32 regula la solución extrajudicial de conflictos: 1 . El prestador y el destinatario de servicios de la sociedad de la información podrán someter sus conflictos a los arbitrajes previstos en la legislación de arbitraje y de defensa de los consumidores y usuarios, y a los procedimientos de resolución extrajudicial de conflictos que se instauren por medio de códigos de conducta u otros instrumentos de autorregulación. 2. En los procedimientos de resolución extrajudicial de conflictos a que hace referencia el apartado anterior, podrá hacerse uso de los medios electrónicos, en los términos que establezca la normativa específica".

En España, la modalidad de resolución extrajudicial de controversias más utilizada es la de la Negociación, Mediación y Arbitraje del Sistema Arbitral de Consumo, dependiente del Instituto Nacional de Consumo. Un sistema extrajudicial de resolución de conflictos a través del cual, sin formalidades especiales y con carácter vinculante y ejecutivo para ambas partes, se resuelven las reclamaciones de los consumidores y usuarios, siempre que el conflicto no verse sobre intoxicación, lesión o muerte o existan indicios racionales de delito. La adhesión al sistema arbitral de consumo Da derecho al empresario a ostentar un distintivo oficial en todas sus comunicaciones incorporándose al Registro público de Empresas adheridas al Sistema Arbitral de Consumo. El uso de este distintivo oficial es un elemento adicional de calidad, que el empresario o profesional ofrece a los consumidores: la posibilidad de resolver las reclamaciones a través de un procedimiento rápido, eficaz, gratuito y con fuerza ejecutiva. El arbitraje de Consumo Electrónico (Real Decreto 231/2008, de 15 de febrero, por el que se regula el Sistema Arbitral de Consumo) Permite que todas las actuaciones, incluidas las notificaciones, puedan realizarse por medios electrónicos, sin perjuicio de que alguna actuación arbitral deba practicarse por medios tradicionales. Este sistema permite mayor rapidez, no hay necesidad de fijar un lugar de celebración del mismo ni de presentar las pruebas en forma escrita. Los documentos requeridos pueden ser enviados por e-mail, evitando así los gastos de correo, fax, fotocopias, etc.

46. Básicamente, este nuevo Real Decreto de 2005 se promulga atendiendo un requerimiento de incompetencia realizado por el Gobierno de la Generalitat de Cataluña, solicitando que se reconozca la competencia de las Comunidades Autónomas respecto al procedimiento y funciones ejecutivas en ellos regulados. En definitiva, piden se añada la referencia a las lenguas cooficiales en el territorio español y que se reconozcan las competencias de las Comunidades Autónomas respecto de los actos de concesión y de retirada del distintivo.

47. El procedimiento de evaluación que se prevea, que podrá realizarse íntegramente por medios electrónicos, deberá garantizar:

a) La independencia e imparcialidad del órgano responsable de la evaluación y sanción.

b) La sencillez, accesibilidad y gratuidad para la presentación de quejas y reclamaciones ante dicho órgano por los eventuales incumplimientos del código de conducta y la celeridad en todas las fases del procedimiento

c) La audiencia del reclamado y el principio de contradicción 
d) Una graduación de sanciones que permita ajustarlas a la gravedad del incumplimiento. Esas sanciones deberán ser disuasorias, y podrá establecerse, en su caso, su publicidad o la suspensión o expulsión de la adhesión al código o a la entidad promotora, en el caso de que se trate de prestadores de servicios integrados en ella.

e) La notificación al denunciante de la solución adoptada.

Las sanciones que se impongan a los prestadores de servicios por incumplimiento de los códigos de conducta deberán notificarse trimestralmente al órgano administrativo competente para la concesión y retirada del distintivo. Cuando dichas sanciones supongan la expulsión de la adhesión al código o la suspensión de sus derechos, las notificaciones deberán realizarse en el plazo de los cinco días siguientes a la adopción de la sanción (art.8.3).

48. El Instituto Nacional de Consumo publicará en su página de Internet los códigos de conducta a los que se conceda el distintivo regulado en el citado Real Decreto; la relación de las entidades promotoras de dichos códigos y la de los prestadores de servicio adheridos; las sanciones impuestas a los prestadores de servicios por incumplimiento, si son públicas, especialmente cuando lleven aparejada la suspensión o expulsión del prestador de servicios del código o de la entidad promotora o la retirada del "distintivo público de confianza en línea", y la dirección establecida para la presentación de quejas por incumpliendo de los códigos y la de los órganos de resolución extrajudicial de conflictos previstos en los códigos de conducta (art.13.1).

El Real Decreto establece unas actuaciones de control sobre la utilización del distintivo. "Cuando la utilización del 'distintivo publicidad de confianza en línea', contraviniendo lo dispuesto en este real decreto, constituya publicidad ilícita, el Instituto Nacional de Consumo y los órganos competentes en materia de consumo de las comunidades autónomas podrán iniciar el procedimiento sancionador o promover el ejercicio de las acciones judiciales que procedan [...] (art.14).

49. Los socios preferentes de Confianzaonline son Adigital (Asociación Española para la Economía Digital) y AECEM (Asociación española para la Autorregulación de la Comunicación Comercial). El distintivo reconoce la transparencia y credibilidad de las webs adheridas, acreditando su compromiso ético y social a todos los usuarios. Entre sus objetivos destaca: a) Aumentar la confianza de los consumidores en el uso de Internet y los nuevos medios digitales; b) Ofrecer un magnífico instrumento a las entidades públicas y privadas para mostrar, a través de su adhesión a este sistema, su compromiso ético con la sociedad en sus actividades de comunicación comercial, comercio, transacciones económicas con consumidores, seguridad en las transacciones, protección de menores, accesibilidad, uso, fiabilidad, privacidad y protección de datos y, de este modo, recabar la necesaria confianza de los consumidores en los nuevos medios; c) Superar con ordenaciones globales la actual fragmentación legislativa además de dotar a la publicidad interactiva y el comercio electrónico de un instrumento de resolución extrajudicial de controversias rápido, económico y eficaz que es una útil herramienta para los consumidores y las empresas; e) Concretamente, sus actividades afectan a: comunicación comercial, comercio / transacciones económicas con consumidores y seguridad, protección de menores, accesibilidad, usabilidad y privacidad y protección de datos

50. Los sistemas de autorregulación deben gozar de credibilidad entre la industria y los consumidores, y esta credibilidad vendrá determinada por la eficacia que demuestren como instrumento de resolución de controversias y de promoción de elevados niveles de corrección ética. Es por ello que se atendió la necesidad de que este sistema estuviera constituido por dos elementos básicos en todo sistema de autorregulación: de un lado, un código de conducta, en el que se recogen las normas que los miembros adheridos se comprometen a observar y cumplir, y de otro lado, un mecanismo de control de la aplicación de tales normas, que reúne expertos independientes e imparciales, con competencia para resolver las eventuales reclamaciones y controversias que pudieran surgir. En cumplimiento de estas dos líneas inspiradoras, confianzaonline está basado en cuatro pilares:

$\left.1^{\circ}\right)$ Un conjunto de normas deontológicas recogidas en el "Código Ético de Confianza Online"; $2^{\circ}$ ) Un mecanismo de aplicación de esas reglas que se encarga de resolver las controversias y reclamaciones que se presenten. Este sistema se basa en la actividad de dos órganos: el Jurado de Autocontrol de la Publicidad, para todas las cuestiones relacionadas con las comunicaciones comerciales, privacidad, protección de datos y protección del menor, y la Junta Arbitral Nacional de Consumo, para las cuestiones de carácter contractual con los consumidores que se puedan suscitar, previo intento de 
mediación por parte de AECEM; $3^{\circ}$ ) Una Secretaría que se encargará de los aspectos de tramitación y procedimientos a la que se dirigirán las reclamaciones presentadas por pretendidas infracciones de las normas de este Código; $4^{\circ}$ ) Y un Sello de Confianza que permita identificar a las empresas y compañías adheridas.

Concretamente, el código ético de confianzaonline está formado por un conjunto de normas deontológicas, y se divide en dos grandes áreas: comunicaciones comerciales y comercio electrónico con consumidores, sin olvidar la necesaria atención que merece la protección de datos personales en el desarrollo de ambas actividades. Mediante el Código Ético de Confianza Online, todas estas entidades manifestaron su serio compromiso por crear y sostener, en el marco de la defensa del ejercicio de la ética y deontología profesional, un sistema integral de autorregulación relativo a la publicidad y a las transacciones comerciales con los consumidores en los medios electrónicos de comunicación a distancia.

51. Este Distintivo era concedido por el Instituto Nacional del Consumo a aquellos sistemas de autorregulación que ofrecieran especiales garantías de protección a los consumidores y usuarios en el ámbito de los nuevos medios. Con la recepción de este Distintivo, confianza online se convierte en el primer organismo de autorregulación público-privado de ámbito nacional merecedor del mismo (B.O.E. de 25 de Octubre de 2005). Al pulsar sobre el Sello de Confianza, los usuarios tendrán acceso a una ficha específica de la empresa que esté luciendo el Sello dentro de la página web de confianza online) en la que se encuentra toda la información legal y de contacto de la entidad adherida al sistema. La ficha especificará los compromisos que la entidad asume al adherirse a confianza online, y por último, se permite la presentación de reclamaciones online contra la misma.

Hay una tabla en la que se establecen las diversas modalidades para el pago de la cuota: a) Si participan de AECEN o de Autocontrol, tienen un descuento del $100 \%$ de la cuota anual; b) Si se trata de Empresas públicas, privadas y profesionales, hay varios tramos dependiendo del criterio de la facturación anual. Por ejemplo, las empresas que facturan menos de 1.000.000 € pagarían una cuota anual de 295€ + IVA; las empresas que facturan más de 25.000.001 € pagarían 3.500 $€+$ IVA de cuota anual; c) Administraciones públicas también tienen sus correspondientes tramos (Criterio: número de habitantes). Así, Hasta 20.000 habitantes / Otras entidades Públicas (Colegios Profesionales, Universidades...), pagarían una cota anual de $295 €+$ IVA; De 20.000 a 500.000 habitantes, una cuota de 550 $€$ + IVA; Más de 500.000 habitantes / Administración General del Estado, con un coste de $1.250 €+$ IVA.

El Proceso de Verificación dará comienzo con el envío del Informe de Verificación por parte de la Secretaría Técnica de Confianza Online, en el que se valorará el grado de adecuación del sitio web al Código Ético. En el caso de detectarse incumplimientos, el informe incluirá una serie de medidas correctoras. El periodo de Verificación dependerá de la velocidad de respuesta y adaptación de cada solicitante y se extenderá hasta un máximo de tres meses. En el caso de que durante este periodo el solicitante opte por no adecuar su sitio web o desista de su solicitud, se retendrá el $40 \%$ del importe ingresado, por gastos de gestión. Si durante dos meses no se recibe respuesta al Informe ni a los requerimientos efectuados se dará por finalizado el Proceso de Verificación sin adhesión y sin derecho a reclamar abono de la cuota ingresada.

52. Este es el caso de Confianza Online, según explica "El crujidero" en Internet, en un escrito de fecha de 07.06.2010, que titula "Des-confianza on line". Las razones que esgrime son: a) No publican el código ético tal como es exigido a las empresas adheridas; b) No publican las condiciones de adhesión, entendidas como condiciones de contratación del sello donde se deberían especificar, por ejemplo, los plazos para la rectificación de errores; c) No atienden las solicitudes de las empresas adheridas respecto al código ético y las condiciones de contratación; d) Hay incoherencias entre lo que publican en su pagina web y el código ético, por ejemplo, en la sección de preguntas frecuentes dicen que la reclamación" Es absolutamente gratuita ya que quienes costean los procedimientos para tramitar una reclamación son las entidades adheridas", pero en el código ético no dice nada de esto y tampoco en las condiciones de contratación (que no existen); e) Su página web incumple su propio código ético, por ejemplo, ninguno de los enlaces externos en su pagina web esta correctamente indicado; f) Han demostrado un desconocimiento manifiesto de la red: Fallos de seguridad en su página web; Errores de configuración de sus certificados SSL, incluso después de varios meses siguen teniendo mal el certificado de https://www.confianzaonline.org ; g) En su código ético no recomiendan el uso de certificados SSL para cifrar y proteger las transmisiones de datos personales, la publicación 
de las políticas de privacidad usando protocolos ya existentes como P3P, el uso de medidas de seguridad para la protección de datos personales o incluso auditorias de seguridad; h) El sello tampoco garantiza ayudar a vender más en internet. Generalmente, ni aumentan las ventas cuando se tiene el sello ni disminuyen cuando dejan de tenerlo. El tener el sello en realidad solo sirve para hacerles publicidad a través de enlaces a su página web y engrosar sus bolsillos.

\section{BIBLIOGRAFÍA}

CORTINA, A., "Intervención- Conferencia", en AA.VV., Jornadas sobre Ética pública, Madrid, Instituto Nacional de Administración Pública, 1997.

DIEGO, O., "Fortaleza ética en gobernantes y funcionarios de la Administración pública" en Revista Ética Administrativa, IAP del Estado de Quintana Roo, México, 2004.

. "El control de conductas corruptas mediante el fortalecimiento de valores éticos", en Ética y servicio público, en PEÑA, L., AUSíN, T. y DIEGO, O., (edts.), Madrid, Plaza y Valdés editores, 2010.

DOMENĖCH, A., "Ética pública y control democrático. La función de la ética pública en el funcionamiento de la democracia", en Ética pública. Desafíos y propuestas, en IZQUIERDO, A., y LAGO, S. (Edts.), Barcelona, Edicións Bellaterra, 2008, pp.11-19.

GIL IBÁÑEZ, A. J., “¿Están preparados los políticos para gobernarnos?” en Notario del siglo XXI, ํo32, Madrid: Revista del Colegio Notarial de Madrid, 2010.

GONZÁLEZ PÉREZ, J., Corrupción, ética y moral en las Administraciones públicas, Madrid, Thomson-Civitas, 2006.

GOÑI SEIN, José Luis, Ética empresarial y código de conducta. Madrid, La Ley.

GRACIÁN, B., El arte de la prudencia. Madrid, Temas de Hoy, 1993.

LABRADA RUBIO, V., Ética en los negocios, Madrid, ESIS Editorial, 2010.

NAESSENS, H., "La ética pública y su proyección en el valor de la transparencia", en Ética y servicio público, en PEÑA, L., AUSíN, T. y DIEGO, O. (edts.), Madrid, Plaza y Valdés editores, 2010.

OLLERO, A., "Responsabilidades políticas y razón de Estado", en Papeles de la Fundación para el análisis y los estudios sociales, núm.31, pp.19 y ss

OTERO PARGA, M., "La Ética del mediador", en Mediación y resolución de conflictos: técnicas y ámbitos, en SOLETO MUÑOZ, H. (Directora), Madrid, Tecnos, 2011, p.88. 
PECES-BARBA, G., Ética pública y Derecho. Discurso de Ingreso en La Academia de Ciencias Morales y Políticas, 1993;

"Ética pública-ética privada", en Anuario de Filosofía del Derecho XIV, Madrid, 1994.

Dykinson, 2010.

Diez lecciones sobre Ética, Poder y Derecho, Madrid,

PEÑA, L., T. AUSíN y DIEGO, O. (edts.), Ética y servicio público, Madrid, Plaza y Valdés editores, 2010.

PICADO, S., "Ética pública y corrupción", en El Derecho público a comienzos del siglo XXI. Estudios en homenaje al Profesor A. R. Brewer Carias, ThomsonCivitas, 2003, III.

RODRÍGUEZ ALBA, J., "Ideología y política en la ética pública”. La cuestión del Estado ético" en Ética y servicio público, en PEÑA, L., AUSíN, T. y DIEGO, O. (edts.), Madrid, Plaza y Valdés editores, 2010.

VELASQUEZ, M.G., Ética en los negocios. Conceptos y casos, 6ª ed., México, Pearson, 2006.

Recebido para publicação: 05/11/2011

Aceito para publicação: 13/12/2011 